\title{
Simulation of Closed Loop Speed Control of CUK Converter FED BLDC Motor with PI Controller
}

\author{
Y.Divya, P.Siva Prasad
}

\begin{abstract}
The BLDC applications are limited due to the present of torque ripples in the output during the speed control operation. This paper introduces a Proportional Integra 1(PI) control approach for controlling of motor speed using CUK BLDC motor is fed with the CUK converter for speed control applications. The pulses to the CUK converter are provided through the PI controller. CUK Converter is used for low power applications and high efficient operation of SMPS power circuit. To get constant output voltage, Load current, input voltage and reference voltages are taken as feedback signals. Matlab/Simulink software is used in the execution of this project.
\end{abstract}

Index Terms- BLDC, CUK, PI Controller, Speed, Torque, VSI.

\section{INTRODUCTION}

Brushless DC (BLDC) motors are chosen for low power applications due to its high performance, noiseless operation, compact size and low maintenance. The BLDC motors are mostly used in the aviation, medical, aircraft, vehicular and robotic applications. Torque ripples are one of the major drawbacks of the BLDC motors which occur during variable speed operations. In recent trends due to the development of technology in power electronic devices and controllers the ease of providing controls and developing the brushless permanent magnet motors had increased. BLDC motor provides square wave signal at output which is similar to the DC motor. Permanent magnet in the motor helps to provide compact size of the motor and increases its efficiency and reliability. [1]

BLDC motor has high torque to inertia ratio, low maintenance and provides wide range of speed control. The permanent magnet in the BLDC motor acts as rotor and provides continuous flux and the stator contains three phase windings. BLDC motor has low commutation losses due to the presence of inbuilt electrical commutation. BLDC motor results in the generation of low PF and high harmonics when it is excited by uncontrolled bridge rectifiers. Hence these motors are excited by controlled AC/DC converters for

Manuscript revised on November 5, 2019 and published on November 15, 2019

Y.Divya, PG Scholar, Dept of EEE, G. Narayanamma Institute of Technology \& Science (For Women), Shaikpet, Hyderabad, TS, India. E-mail: -yennamdivya1996@gmail.com.

P.Siva Prasad, Assistant Professor, Dept of EEE, G. Narayanamma Institute of Technology \& Science (For Women), Shaikpet, Hyderabad,

TS, India., E-mail: sivaprasadaits@gmail.com. providing better power quality. The semiconductor devices used in the converters injects current harmonics and distorted voltage waveforms which results in low power quality and hence required high power filters.

CUK converter is one of the types of chopper circuit which has an output voltage magnitude either greater than or less than the input voltage magnitude. Moreover, the CUK converter uses coupled inductors to reduce the current ripple along with a capacitor to couple the energy. It is also inverting circuit generated from the duality principle of buck-boost converter[7].

The most important objective of the inverter is to create an ac output voltage waveform from a dc power supply at fixed or variable frequency used for high power applications .The types of waveforms generated in the inverter are required for few applications such as commutation torque control, variable speed drives, harmonic reduction, Flexible AC Transmission Systems (FACTS) devices and voltage compensators. For sinusoidal waveform, the magnitude, frequency, and phase of the inverter should be controlled. The output voltage waveform of basic inverter is mainly depending on the width of the pulse and gating signals should be sinusoidal.

The Proportional integral method is a control system that offers various benefits like stability, even for wide line and output variations, scaling back the steady state error, robustness, sensible dynamic response and easy implementation. The primary benefit of PI control schemes is its harder response to plant/system. The parameter variations that result in invariant dynamic and static response within the ideal case The PI controller to be developed for the control of CUK convertor permits to regulate the dc output voltage.

\section{CUK CONVERTER}

CUK converter is a DC/DC converter which steps up and steps down the voltage. It is used as both boost and buck converter which is coupled by the capacitor [8].

It functions similar to the buck-boost converter with additional control of inverting output. Capacitors are used as voltage couplers rather than inductors. Figure shown below provides the circuit diagram of CUK converter $[9,10]$. 


\section{E-ISSN: 2321-9637}

\section{Available online at www.ijrat.org}

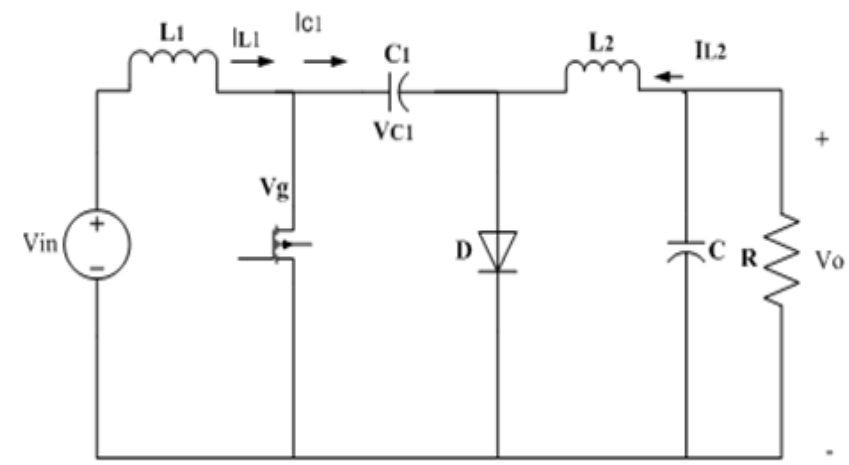

Fig.1 Circuit diagram of CUK converter

The average output voltage is given by

For calculating $\mathrm{L}_{1}, \mathrm{~L}_{2}, \mathrm{C}_{1}$ and $\mathrm{C}_{2}$

$\mathrm{L}_{1}=\frac{\mathrm{V}_{\text {in }} \mathrm{D}}{\mathrm{f}_{\mathrm{g}} \Delta_{\mathrm{L}_{1}}}, \mathrm{~L}_{2}=\frac{\mathrm{V}_{\text {in }} \mathrm{D}}{\mathrm{f}_{\mathrm{g}} \Delta_{\mathrm{L}_{2}}}$

$\mathrm{C}_{1}=\frac{\mathrm{I}_{\mathrm{s}}(1-\mathrm{D})}{\mathrm{f}_{\mathrm{s}} \Delta_{\mathrm{v}_{\mathrm{C}_{1}}}}{ }_{,} \mathrm{C}_{2}=\frac{\mathrm{D}\left(\mathrm{V}_{\text {in }}\right)}{8 \Delta \mathrm{V}_{\mathrm{C}} \mathrm{f}_{\mathrm{s}}{ }^{2} \mathrm{~L}_{1}}$

Table 1 Specifications of CUK Converter

\begin{tabular}{|c|c|}
\hline \multicolumn{2}{|c|}{ Parameters of Cuk Converter } \\
\hline Input Voltage & $220 \mathrm{~V}$ \\
\hline Switching Frequency & $50 \mathrm{Khz}$ \\
\hline Inductor(L1) & $2.2 \mathrm{Mh}$ \\
\hline Inductor(L2) & $1.1 \mathrm{mH}$ \\
\hline Capacitor(C1) & $15 \mu \mathrm{F}$ \\
\hline Capacitor(C2) & $2500 \mu \mathrm{F}$ \\
\hline
\end{tabular}

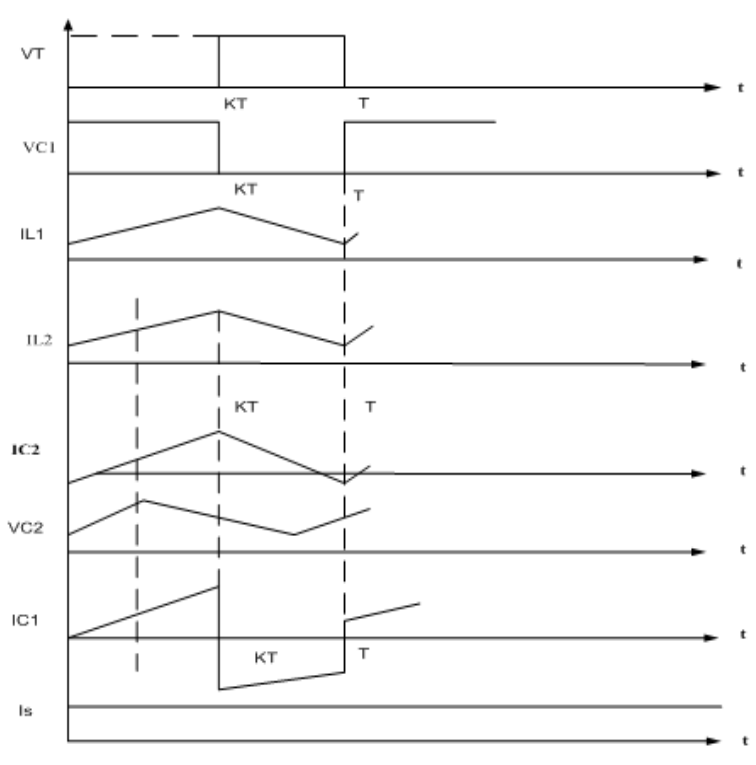

Fig.2 Waveforms of CUK converter

\section{A. Proportional-Integral CONTROL TECHNIQUE}

The PI controller calculates error between output and reference values and provides differential values for the control feedback to the CUK converter which is determined in MATLAB/Simulink. Proportional-Integral controller mode results from the combination of the proportional and also the integral mode. The PI controller has varied gains of $\mathrm{kp}$ and $\mathrm{ki}$ and produces control signals which controls the speed of the motor.

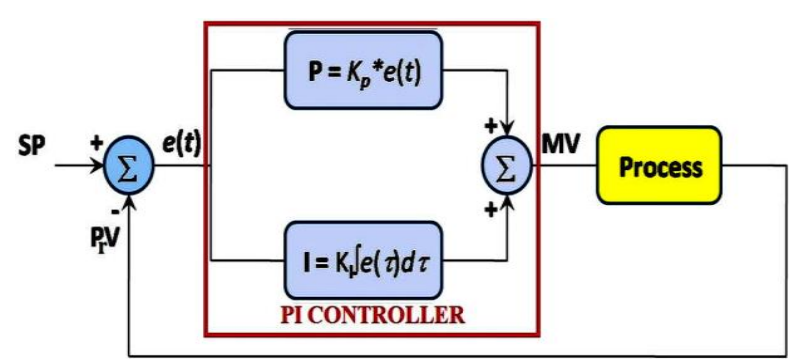

Fig 3 Block diagram of Closed loop PI Controller

\section{Three Phase Voltage Source InVerter}

A 3-phase inverter is employed to convert a DC input voltage into a 3-phase AC output voltage. There are mostly three arms in general deferred with an angle of $120^{\circ}$ and produces a three-phase AC supply. The each and every switch of the inverter has a duty ratio of $50 \%$ and switching normally occurs before interval of $60^{\circ}$. Three phase inverters are frequently operated in to two major kinds of modes of conduction, i.e. 120 degree angle conduction mode and 180 degree angle conduction mode. In this anticipated system 120 degrees angle mode of conduction is used [6]. 


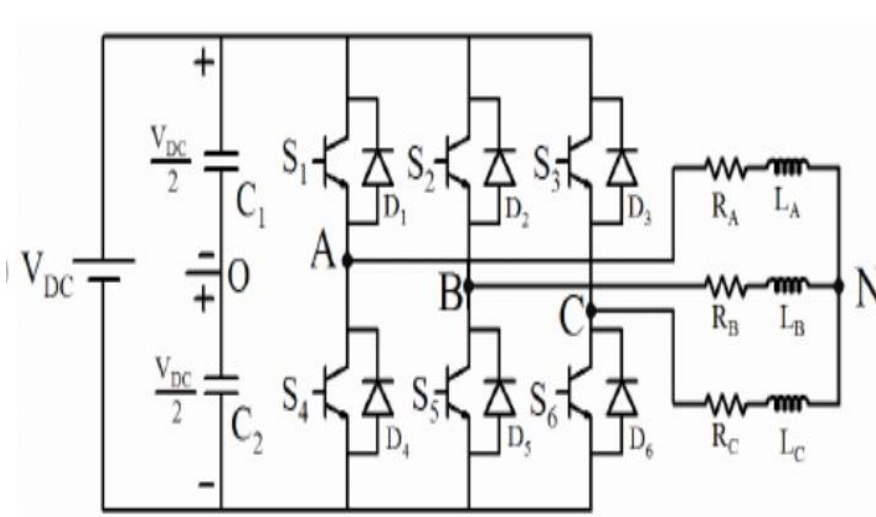

Fig 4 Three Phase inverter

The voltage source inverter simply produces a square voltage waveform due to its simple turn on and off nature as different to the sinusoidal waveform that is the standard waveform of an AC power supply. By means of Fourier series, periodic waveforms are presented as the addition of the infinite series of sine waves. The sine wave that has the analogous frequency as that of the original waveform is known as primary component and other waves are called as harmonics that include in series with connected multiples of the fundamental frequency.

\section{BLDC MOTOR}

The primary principle of BLDC motor is to generate a magnetic field into a rotor to rotate by using permanent magnets connected through a commutator and to produce the continuous output torque. For industrial, commercial and domestic application mainly BLDC motor is used. BLDC motors can produce continuous output torque with a three phase inverter drive. In case of BLDC motor modelling the back EMF is measured under ideal condition[5].

The final electromagnetic torque of BLDC motor is given by $\mathrm{T}_{\mathrm{e}}=\frac{\mathrm{k}_{\mathrm{e}}}{2}\left[\mathrm{~F}\left(\theta_{\mathrm{e}}\right) \mathrm{i}_{\mathrm{a}}+\mathrm{F}\left(\theta_{\mathrm{e}}-\frac{2 \pi}{\mathrm{a}}\right) \mathrm{i}_{\mathrm{b}}+\mathrm{F}\left(\theta_{\mathrm{e}}-\frac{4 \pi}{\mathrm{a}}\right) \mathrm{i}_{\mathrm{c}}\right]$

Due to simple operation, the centrifugal pump is employed. In induction motor energy is converted into the kinetic energy in the form of liquid flow by accelerating the revolution.

A. Mathematical Modelling of BLDC MOTOR

The BLDC motor is designed to supply electrical commutation instead of mechanical commutation for better efficiency and extended life. In BLDC motors the commutator is being replaced by the inverter and thus it is also known as "inverted DC motors". The rotor winding is replaced by the permanent magnets where as the input of the stator is provided through the three phase inverter $[3,4]$. The BLDC motor is the combination of permanent magnet motor, a stator with three phase winding and the power driving inverter circuit. Mathematical modelling includes the combination of differential equation model, transfer function model, and state-space model. The steady and dynamic characteristics are mathematically analyzed and hence provided the current and the torque variations during commutation [2].

The line to line voltage equations which are governing the BLDC motor are given by

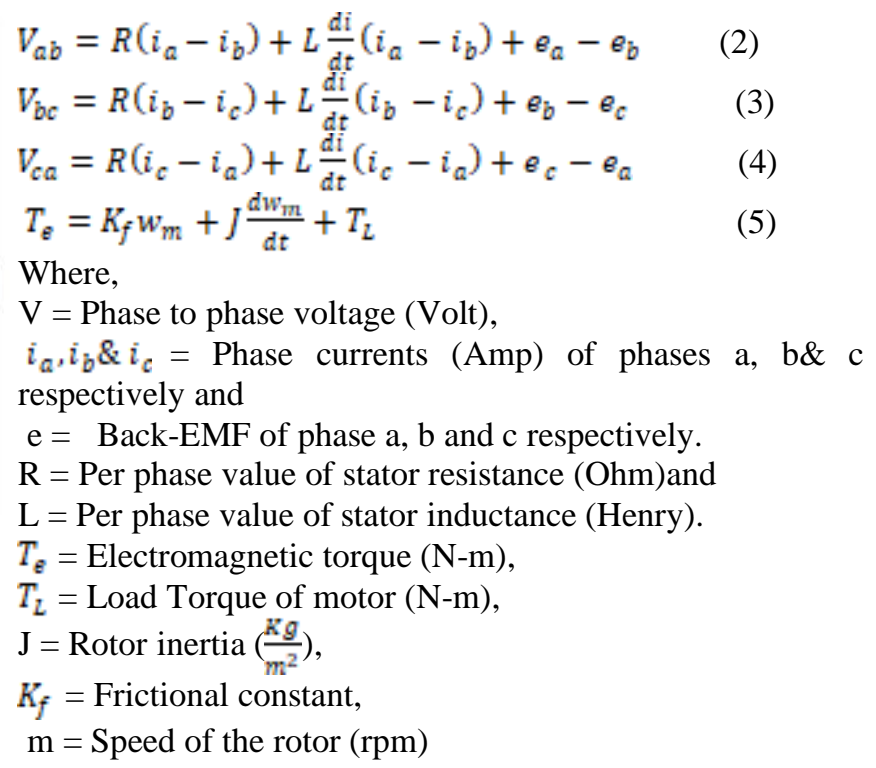

Where,

$\mathrm{V}=$ Phase to phase voltage (Volt),

$i_{\mathbb{Q}^{x}} i_{b} \& i_{a}=$ Phase currents (Amp) of phases a, b\& c respectively and

$\mathrm{e}=$ Back-EMF of phase $\mathrm{a}, \mathrm{b}$ and $\mathrm{c}$ respectively.

$\mathrm{R}=$ Per phase value of stator resistance $(\mathrm{Ohm})$ and

$\mathrm{L}=$ Per phase value of stator inductance (Henry).

$T_{e}=$ Electromagnetic torque $(\mathrm{N}-\mathrm{m})$,

$T_{L}=$ Load Torque of motor $(\mathrm{N}-\mathrm{m})$,

$\mathrm{J}=$ Rotor inertia $\left(\frac{\mathrm{Kg}}{\mathrm{m}^{2}}\right)$,

$K_{f}=$ Frictional constant,

$\mathrm{m}=$ Speed of the rotor $(\mathrm{rpm})$

The rotor reference frame equations in terms of $d-q$ frame as shown below

$$
\begin{aligned}
& \theta_{a}=\frac{k_{a}}{2} w_{m} F\left(\theta_{\theta}\right) \\
& \theta_{b}=\frac{k_{g}}{2} w_{m} F\left(\theta_{\theta}-\frac{2 \pi}{a}\right) \\
& \theta_{b}=\frac{k_{g}}{2} w_{m} F\left(\theta_{\theta}-\frac{4 \pi}{a}\right)
\end{aligned}
$$

Where the symbols

$\mathrm{k}=$ Back emf constant,

$\theta=$ Electrical rotor angle and

$\mathrm{w}=$ Mechanical speed of rotor

Where the symbol $K_{\mathrm{t}}$ is torque constant

The function $\mathrm{f}($ ) generates trapezoidal waveform of back EMF

$$
F\left(\theta_{0}\right)=\left\{\begin{array}{c}
1,0 \leq \theta_{0} \leq \pi \\
1-\frac{6}{\pi}\left(\theta_{0}-\frac{2 \pi}{3}\right), \frac{2 \pi}{3} \leq \theta_{\theta} \leq \pi \\
-1, \pi \leq \theta_{0} \leq \frac{5 \pi}{3} \\
-1+\frac{6}{\pi}\left(\theta_{0}-\frac{5 \pi}{3}\right), \frac{5 \pi}{3} \leq \theta_{0} \leq 2 \pi
\end{array}\right.
$$


International Journal of Research in Advent Technology, Vol.7, No.10, October 2019

E-ISSN: 2321-9637

Available online at www.ijrat.org

Table 2 electrical parameters of BLDC motor modeling

\begin{tabular}{|c|c|c|}
\hline Parameter & Symbol & Value \\
\hline Stator resistance & Rs & $1.43 \Omega$ \\
\hline Stator Inductance & Ls & $9.4 \mathrm{MH}$ \\
\hline $\begin{array}{c}\text { Permanent } \\
\text { Magnetic fux }\end{array}$ & A & $0.175 \mathrm{~Wb}$ \\
\hline $\begin{array}{c}\text { Pole pairs } \\
\text { Moment of } \\
\text { inertia }\end{array}$ & $\mathrm{P}$ & 4 \\
\hline T & $0.002 \mathrm{kgm}-2$ \\
\hline
\end{tabular}

\section{SIMULATED RESULTS}

The CUK Converter connected to BLDC motor simulation diagram is shown in figure8.

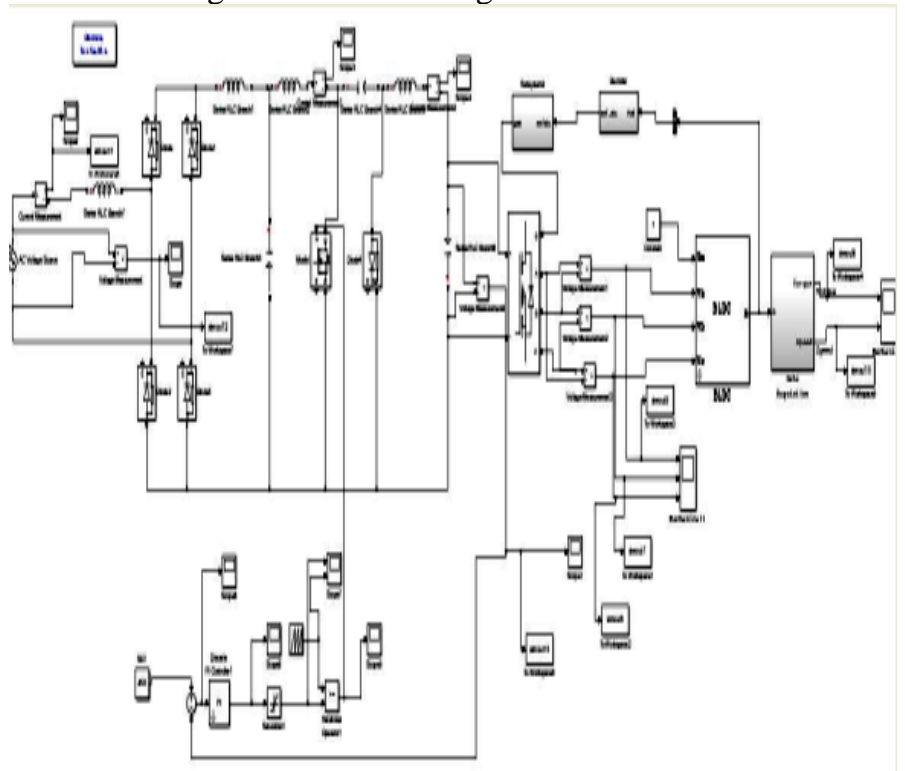

The CUK output value increases approximately to 300volts.

Fig.6 Supply voltage of the system

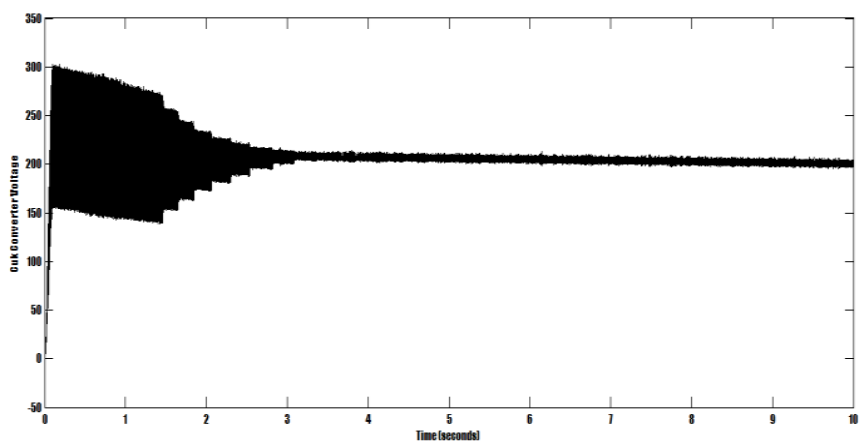

Fig.7 Cuk converter output voltage

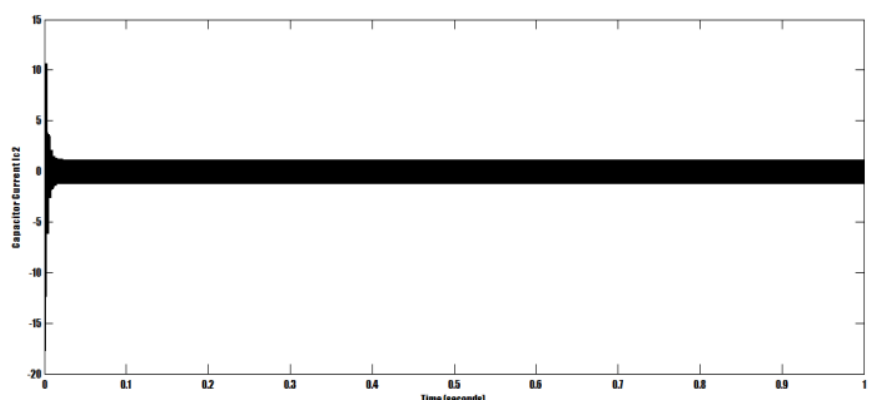

Fig.8 Filter capacitor current of Cuk Converter

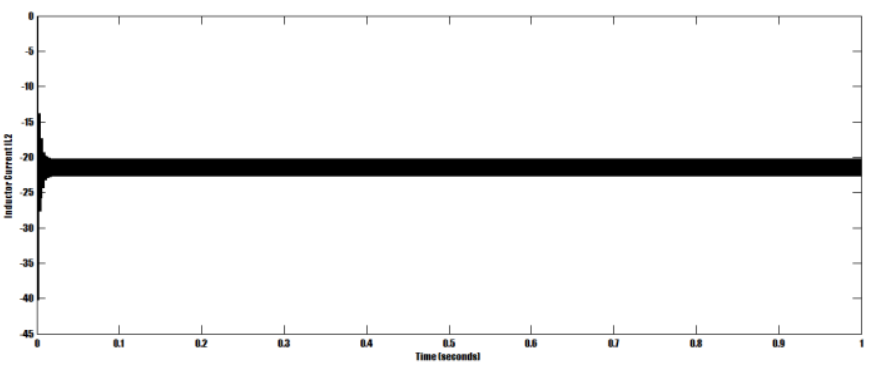

Fig 9 The Filter inductor current $\left(\mathrm{IL}_{2}\right)$ waveforms of $\mathrm{Cuk}$ Converter

Fig 5 Modelling of CUK Converter fed BLDC Motor 


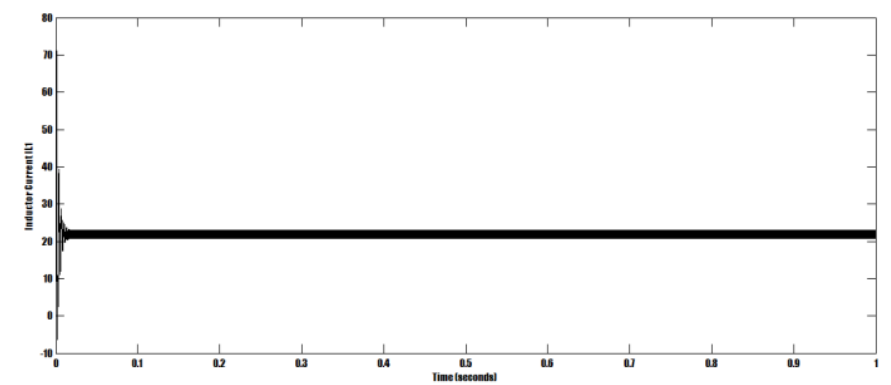

Fig 10 The Input inductor $\mathrm{IL}_{1}$ current of Cuk converter

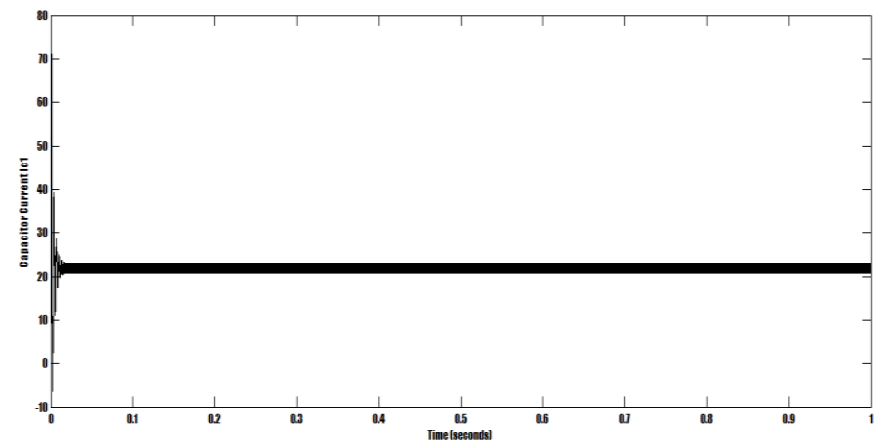

Fig 11 The Input inductor $\mathrm{IL}_{1}$ current of Cuk converter
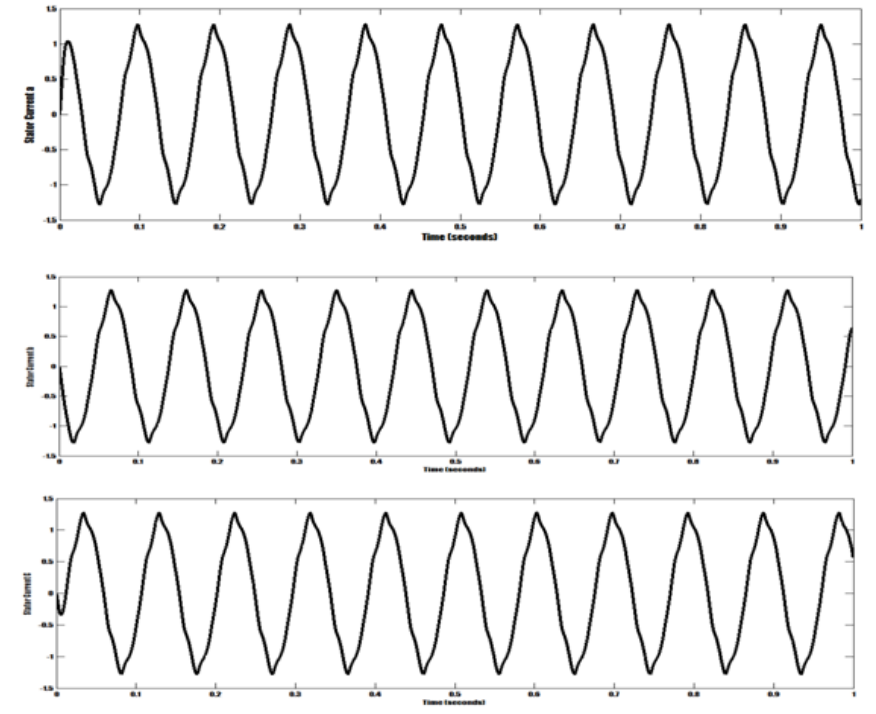

Fig.12 Three phase stator currents of BLDC motor

The rated speed of the brushless dc motor at no-load torque is equal to $1500 \mathrm{rpm}$.
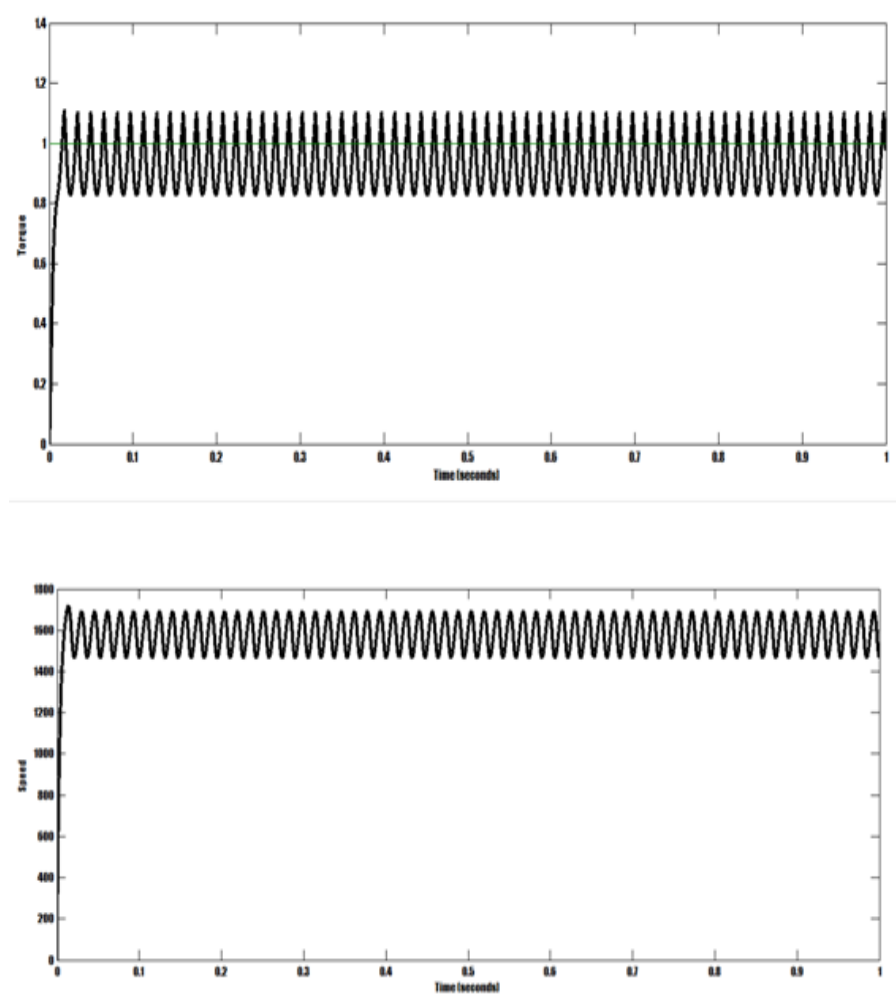

Fig. 13 Speed and electromagnetic torque responses of BLDC Motor
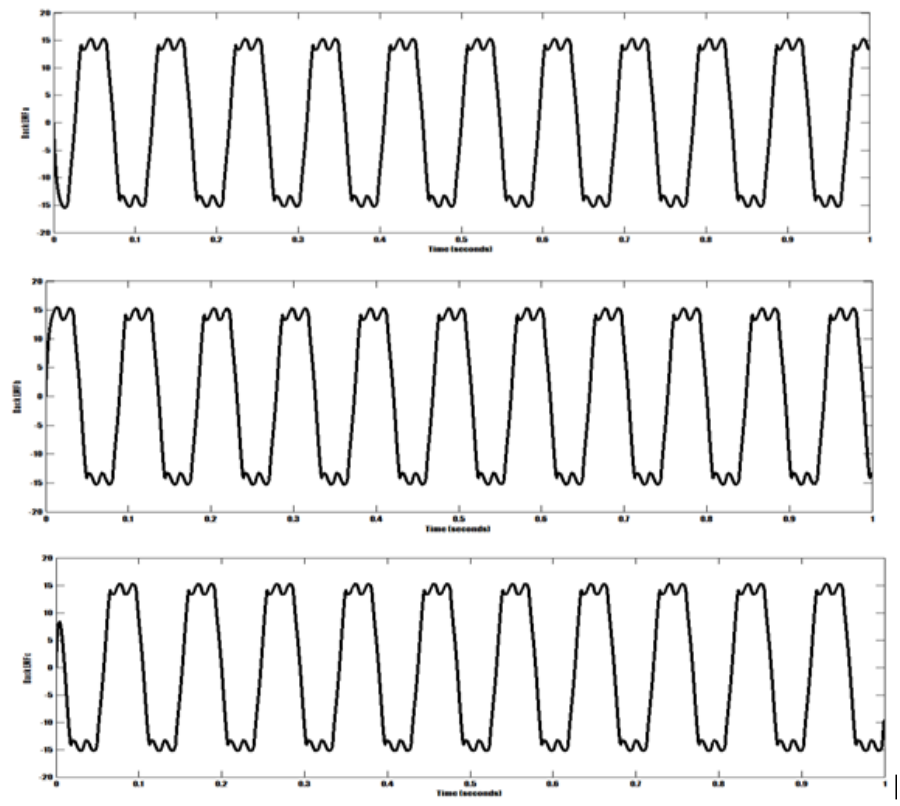

Fig 14. Back EMF waveforms of three phase of BLDC motor

\section{CONCLUSION}

The PI controller fed CUK converter is proposed for the Speed control and torque ripple reduction of BLDC motor drive system. Voltage Source Inverter with three phase is used as an electronic commutation switch for BLDC electric motor. The CUK converter voltage is varied by varying DC link capacitor by setting a corresponding constant value of reference voltage through PI controller to get control over the 


\section{Available online at www.ijrat.org}

BLDC motor .From the simulation results it is observed that the proposed system has high speed with effectively low stator current and torque ripples.

\section{REFERENCES}

[1] Hemchand Immaneni," Mathematical Modelling And Position Control Of Brushless Dc (Bldc) Motor" , IJERA Vol. 3,May-Jun 2013, pp.1050-1057 .

[2] Mukesh Kumar, Bhim Singh and B.P.Singh "Modeling and Simulation of Permanent Magnet Brushless Motor Drives using Simulink", NPSC, 2011.

[3] Manali P. Chavhan, Sanjay M.Shinde," Modeling of Brushless DC Motor with Various Loading Conditions for Electric Vehicle Application”, Volume 12, Issue 6 ,June 2016, PP.64-71.

[4] Santanu Mondal ,Arunabha Mitra, Madhurima Chattopadhyay Mathematical modeling and Simulation of Brushless DC motor with Ideal Back EMF for a Precision speed control Conference Paper August 2015.

[5] Miss Avanti B.Tayade, Modeling and Simulation of A Bldc Motor By Using Matlab/Simulation Tool, IOSR Journal of Electrical and Electronics Engineering PP 55-62,2014.

[6] R.Goutham Govind Raju, S.John Powl, A.Sathishkumar, P.Sivaprakasam Mitigation of Torque for Brushless DC Motor:

\section{AUTHORS PROFILE}

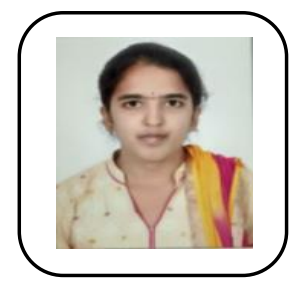

Y.Divya,P.G Student Power Electronics and Electrical Drives, EEE Department, G Narayanamma Institute of Technology and Science. Areas of interest include Power Electronics, Control systems, Electrical Drives..

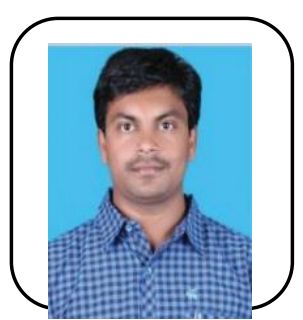

P.Siva Prasad, Currently Working as Assistant Professor at G.Narayanamma Engineering college (for women) affiliated to JNTU, Hyderabad with 8 Years of experience. Completed B.Tech Electrical \& Electronics Engineering in 2008 from AITS, Rajampet affiliated to JNTUH, M.Tech Electrical Engineering in 2010 from NIT Calicut, kerala and Pursuing Ph.D from JNTUH Hyderabad. Areas of interest include Power Electronics.
Modeling and Control International Journal of Scientific \& Engineering Research Volume 3, Issue 5, May-2012.

[7] Rheesabh Dwivedi, , Vinay Kumar Dwivedi, , Rahul Sharma Parametric variation analysis of CUK converter for constant voltage applications ,IJAREEIE,February2014

[8] Vashist Bist ; Bhim Singh, PFC Cuk Converter-Fed BLDC Motor Drive, IEEE Transactions on Power Electronics ( Volume: 30 , Issue: 2 , Feb. 2015 )

[9] Vaiyapuri Viswanathan, Jeevananthan.S, "Commutation Torque Ripple Reduction in BLDC Motor Using Modified SEPIC converter and Three-level NPC inverter", IEEE Transactions on Power Electronics PP(99):1-1 · February 2017.

[10] Abin V Unni, Prof A V Unnikrishnan "PFC CUK CONVERTER FOR PMBLDCM DRIVE”, (IRJET), Volume: 03 Issue: 07 , July-2016 